\title{
Analysis on Status Quo and Countermeasures of the Export of High-tech Products in Fujian
}

\author{
Siwei Dai ${ }^{1}$ Xiujuan $\mathrm{He}^{1, *}$ \\ ${ }^{1}$ School of Economics \& Management, Fuzhou University of International Studies and Trade, Fujian, P.R. China
${ }^{*}$ Corresponding author. Email: 36202964@qq.com
}

\begin{abstract}
With the increasing competition in the international market, the export of high-tech products has gradually become an important factor of the trade competition around the world. Compared with developed countries or provinces, the development of high-tech products lags behind in Fujian Province, especially the development of export trade. Its export trade mainly has the following problems: As the enterprise's innovation ability is insufficient, the investment in research and development is inadequate, it is lack of high-tech related personnel, and the categories of export products are over-concentrated, which restrict the development of the export of high-tech products and affect the foreign trade of high-tech products. This paper studies the status quo and problems of high-tech products export in Fujian Province through comprehensive literature research method, statistical method and data analysis method, etc. In order to achieve the development advantage in the fierce competition of international market, it is believed that Fujian Province should pay attention to the research and development of investments and new products, and the science and technology management departments should strengthen the support and construction of small and medium-sized technology enterprises, as well as pay attention to the training of high-tech talents in the future. The research has certain of practical significance to adjust the economic development and the economic structure in Fujian Province.
\end{abstract}

Keywords: Fujian Province, High-tech products, Export trade, Technical barriers to trade.

\section{INTRODUCTION}

High-tech products refer to the whole new products that meet the national and provincial key scope of hightech technology, and technical fields and product reference catalogue. This product technology is relatively difficult to develop, which economic and social benefits are much higher than ordinary products, so it is gradually valued by many countries. With continuous opening up to the outside world, it will pay more and more attention under the good development momentum of science and technology and economy. As one of the important economic provinces in eastern China, Fujian Province has deeply implemented the innovation-driven development strategy, improved the growth acceleration mechanism of high-tech enterprises, strived to "double" the number of high-tech enterprises and industrial value added, and provided scientific and technological support for Fujian to comprehensively promote the high-quality development. The high-tech products in Fujian Province have developed rapidly in recent years, which have become a major growth point of export trade. However, the economic development of Fujian Province is still in the transformation stage, and it is still in the process of moving from low-end to highend development. In Fujian Province, there are still many problems to be solved in promoting the growth of economic and social benefits, independent innovation ability and international competitiveness [1].

\section{THE STATUS QUO OF DEVELOPING EXPORT TRADE OF HIGH-TECH PRODUCTS IN FUJIAN PROVINCE}

\subsection{The Status of Developing High-tech Products in Fujian Province}

According to the data released by Fujian Provincial Bureau of Statistics, in 2018, it has 19,694 national high-tech industrial enterprises registered in Fujian Province, which is an increase of 5,577 over the previous year, including 3,548 high-tech enterprises, an increase of 494 as compared with 2017, accounting for $18.0 \%$ of the total number of industrial and commercial enterprises in the province; The operating income of high-tech enterprises in Fujian Province reached 774.69 billion yuan, an increase of $14.6 \%$ over the previous 
year; The output value was 730.97 billion yuan, with a year-on-year increase of 80.89 billion.

\subsubsection{The Total Industrial Output Value of the High-tech Enterprises in Fujian Province is Constantly Increasing}

According to the data statistics of the Ministry of Science and Technology, the output value of high-tech products in Fujian Province was 594.19 billion yuan in 2016 , and 6,50.008 billion yuan in 2017, with a year-onyear increase of $9 \%$; In 2018, it reached 730.97 billion yuan, with a year-on-year increase of $12 \%$. The above data states that the total industrial output value of the high-tech products in Fujian Province is increasing year by year, and the growth rate is increasing slowly.

\subsubsection{The Size of High-tech Enterprises in Fujian Province has Continuously Expanded}

Since the establishment of Fuzhou High-tech Industrial Development Zone (the first development zone in Fujian Province) in 1991, by 2018, there are 7 national high-tech development zones in Fujian Province. In 2018, there were 3,548 high-tech enterprises in the High-tech Industrial Development Zone, with 612,000 employees, increased by 39,000 compared with 573,000 in 2017 . In 2019 , there were more than 4,500 high-tech enterprises in Fujian; In 2020, there was 6,476 high-tech enterprises, up by $34.6 \%$ compared to the previous year. In recent decades, the high-tech industry in Fujian Province has been expanding and developing, which played an indispensable role in Fujian economy.

\subsection{The Status Quo of Developing Export Trade of High-tech Products in Fujian Province}

\subsubsection{Export Scale}

According to the Statistical Yearbook of Fujian Province, it can be seen that the exports of the high-tech products in Fujian Province were 99.975 billion yuan in 2017, and the total amount of exporting high-tech products reached to 102.860 billion yuan that had exceeded the $\$ 100$ billion mark. By 2020, the exports of high-tech products reached to 15.648 billion yuan. The export scale of high-tech products shows an increasing trend year by year. The exports of computer and communication technology are the most in the export of high-tech products in accordance with the data analysis issued by the General Administration of Customs. In 2018, the exports of computer and communication technology were 10.404 billion yuan, decreased to 9.908 billion yuan in 2019. However, by 2020, the exports of the computer and communication technology recovered to 10.281 billion yuan. The exports of photoelectric technology are the second. In 2018, its exports were 4.817 billion yuan, which decreased to 4.050 billion in 2019 , and 4.164 billion yuan in 2020 . Therefore, it can be found that although the industrial scale of high-tech products has some ups and downs, and the overall trend is upward.

\subsubsection{Structure of Export Products}

According to the data statistics of the General Administration of Customs P.R. Chia from 2018 to 2020, the export of high-tech products in Fujian Province is mainly concentrated in the products of computer and communication technology, photoelectric technology and aerospace technology. In 2018, the exports of computer and communication technology in Fujian Province accounted for $66.16 \%$; It accounted for $68.35 \%$ in 2019 ; It accounted for $65.70 \%$ in 2020 ; It can be seen that computer and communication technology play a dominant position in the export of high-tech products. The exports of photoelectric technology products accounted for $30.63 \%$ in 2018 ; The exports accounted for $27.93 \%$ in 2019; The exports accounted for $26.61 \%$ in 2020 , down by $4.02 \%$ in 2018 and $1.32 \%$ in 2019. The export proportion of optoelectronic products in the total value of high-tech products has begun to show a downward trend. The exports of aerospace products accounted for $1.17 \%$ of the gross export value of high-tech products in Fujian Province in 2018; The exports accounted for $1.59 \%$ in 2019; The exports accounted for $1.51 \%$ in 2020 , up by $0.34 \%$ compared with 2018, maintaining rapid growth and having considerable room for future development.

\subsubsection{Mode of Trade}

The trade mode of high-tech products in Fujian Province is processing trade and general trade, among which processing trade accounts for a large proportion. In 2018, the export amount of high-tech processing products in Fujian Province was 11.514 billion yuan, accounting for $73.23 \%$ of Fujian high-tech products, of which the import processing trade accounted for $65.6 \%$; In 2019 , the exports were 9.403 billion yuan, accounting for $64.86 \%$, down by $8.37 \%$ year-on-year; In 2020 , the exports were 8.666 billion yuan, accounting for $55.38 \%$, down by $9.48 \%$ year-on-year. In 2018 , the total exports of general trade were 3.490 billion yuan, accounting for $22.19 \%$ of the exports of high-tech products; In 2019, the exports were 4.216 billion yuan, accounting for $29.08 \%$, up by $6.89 \%$ year-on-year; In 2020 , the exports were 6.022 billion yuan, accounting for $38.49 \%$, up by $9.41 \%$ year on year. It can be seen that the trade mode of high-tech products in Fujian Province is gradually changing. 


\subsubsection{Export Areas and Markets}

Looking from the export market of high-tech products, the trade between the countries such as EU, ASEAN, the United States, Japan and Fujian Province is indispensable. Among them, the United States is the country with the most high-tech products exported in Fujian Province, followed by the European Union. The export of high-tech products is 102.86 billion yuan, which is $13.4 \%$ of the export of other goods in the province. Nearly half of the high-tech products exported to the EU and the United States. The amount of products exported to the EU reached 23.8 billion yuan, accounting for $23.1 \%$ in all the countries and regions that exporting high-tech products from Fujian Province; During the same period, the export of technology products to the US was 26.43 billion yuan, which more than that in 2017. The exports to ASEAN were 18.36 billion yuan; The exports to Japan were 10.65 billion yuan. The exports of Fujian to various countries are expanding continuously; however, the trend of exporting to South Korea grows slowly.

\section{PROBLEMS EXISTING IN THE EXPORT TRADE OF HIGH-TECH PRODUCTS IN FUJIAN PROVINCE}

\subsection{Lacking in the Innovation Ability and High-tech Personnel}

Lacking in the innovation ability and high-tech personnel is the key problem restricting the development of high-tech products in Fujian Province. The high-tech products in Fujian Province have not undergone fundamental changes, most of which are still in the form of processing trade. Many high-tech products exported are imitated or improved; the independent property rights are relatively few.

The high-tech industry in Fujian Province is still in the process of development, and the demand for hightech personnel is increasing. To make a product with enough competitiveness, it needs an advanced technical support, and at present, the talent is an important problem restricting the development of Fujian enterprises. However, Fujian Province is not a coastal city with developed high-tech industries. In terms of talent introduction measures, there is a big gap with some cities, such as Guangdong, Zhejiang and Shanghai in China, and the shortage and loss of talents have impeded the development of enterprises in Fujian. [2]

\subsection{Insufficient $R \&$ D Investment Limits Independent Brands}

Input is closely related to output, and when the other conditions are basically the same, the amount of capital input will affect the scale of output. As it can be seen in Table 4-1, the investment in research and development
(R\&D) was 75.37 billion yuan in 2019 , which only ranked 12th in China; The investment strength in research and development (R\&D) is $1.78 \%$, only ranking 15th in China, not exceeding the national average level. Fujian Provincial People's Government has made a relatively insufficient investment in hightech products, which restricts the development of hightech industry, and cannot provide a favorable guarantee for the research and development of independent brand.

There are three reasons for the lack of independent brand research and development: First, it is because that the brand is established too urgent; People do not trust in local brand, and there is a lack of identity of national culture; The phenomenon such as trademark squatting and brand counterfeiting is serious. It is common to find counterfeiting goods, and is difficult to regulate counterfeit behavior, which limit the development of corporate brands [3].

\subsection{The Export Categories Concentrated Restricts the Optimization of Trade Structure}

In Fujian Province, the export categories of hightech products are highly concentrated. There is a big gap between various categories concentrated. The most popular products exported are computer, communications and optoelectronic technologies, and the export of the high-tech products in other categories is obviously relatively small. As a result, the concentration of product categories greatly increases trade risks. At the same time, if there is a crisis occurred due to the concentration of the technology industry, it will have a far-reaching impact on the development of high-tech products in Fujian Province, restrict the innovation-driven development of enterprises, and the concentration of product classification may lead to vicious competition and profit reduction. [4]

\subsection{Sustainable Development is Hindered under Technical Trade Barriers}

On the one hand, the main export market of hightech products in Fujian Province is the United States, the European Union and other countries and regions. These countries and regions have set strict rules for high-tech products, many of which include research and development, production, processing, transportation, sales and processing of products. Most high-tech enterprises in Fujian Province have not established an understanding of the whole process of quality management and environmental management. Many high-tech products do not meet the requirements of relevant technical regulations and standards, and will not be able to enter the relevant international market. [5]

On the other hand, the price advantage is one of the favorable factors that Fujian high-tech products entering the international market competition. The technical 
barriers to trade established by the developed countries require high-tech content. Therefore, it is necessary for Fujian enterprises to constantly improve the production technology and technical equipment, and strengthen the investment requirements, which will directly increase the product cost and reduce the product competitiveness in the international market.

\section{COUNTERMEASURES TO PROMOTE THE EXPORT OF HIGH-TECH PRODUCTS IN FUJIAN PROVINCE}

\subsection{Attaching Great Importance to the Talent Introduction and Training can Promote the Innovation Ability}

The innovative talents who would like to pay more attention to high-tech products is constantly increasing in Fujian Province. The level of the relevant staff has also been greatly improved. In general, the high-tech in Fujian Province has not reached the national average level. First, we shall pay great attention to the training of talents to introduce more high-tech talents. Good benefits provided by the enterprise will motivate employees to do better, which also helps the enterprise to develop a high-tech team. Only by giving full play to the flexibility of talents and providing sufficient innovation skills can achieve the goal of continuous innovation and persistent innovation better in the hightech industries in Fujian Province. Second, it not only needs talent, but also increases high-tech personnel with advanced technology. Therefore, in order to improve the ability of high-tech personnel and enhance the international competitiveness of the enterprise, the enterprises must carefully train high-tech personnel, do a good job in professional training and management. The tangible goods trade depends on the progress and development of the local science and technology industry. In order to better promote tangible goods trade, it is necessary to constantly accumulate high-tech talents, improve innovation ability, and research high-tech products. Therefore, high-tech talent is a major cornerstone of technological innovation [6].

\subsection{Increasing the Investment in Scientific Research can Build a Well-known Local Brand}

In order to improve the innovation ability and develop high-tech products in Fujian Province, it needs the financial assistance from the state to improve the development of the high-tech enterprises. When the funds are adequate and stable, the high-tech team can actively participate in research and development and innovation, which will promote the sustainable and stable development of high-tech products. Because the brand will greatly affect the export of high-tech products, and the research and development of related products, Fujian Province must realize that it is necessary to build local brand. To make the brand become famous, it not only builds a brand, but also strengthens the reputation of the brand. [7]

On the one hand, the integrity brand can be created through the Internet, which will increase the publicity of brand, and enhance the international awareness of local brands. According to the demand of the market, it is necessary to develop the brand marketing strategy and brand positioning, select a geographical location beneficial to the sales in the enterprises, and focus on product innovation to enhance the brand's international reputation

On the other hand, it should strengthen the internationalization of high-tech products in Fujian Province, promote the development and construction of the brand, and build a bridge between domestic and foreign cooperation. The improvement of high-tech innovation ability promotes the development of the industry. Computer, communication technology and photoelectric technology have become the important products of internal cooperation and foreign trade in Fujian Province. The policy of foreign trade in Fujian Province has been fully realized.

\subsection{Developing Product Diversification can Promote the Balanced Development of Export Trade}

In order to improve the current unbalanced development of science and technology, a more reasonable product structure is needed. It is necessary to do the two points as follows. First, some cities can be developed preferentially, and then other cities can be developed together. As two cities with stronger hightech development in Fujian Province, Fuzhou City and Xiamen City can be taken as the first test. It is suggested that Fuzhou and Xiamen can drive the development of other cities together, and the government should also encourage other cities to rapidly develop high-tech industries. It can also introduce high-tech products from other countries or provinces to promote the development of higher-tech products in Fujian Province, improve the diversification of products, and achieve balanced development. Secondly, we should not blindly pay attention to the development of science and technology and damage the environment. Therefore, we should build a good industrial chain and achieve sustainable development [8].

\subsection{Improving the Technical Level of Products can Actively Deal with Trade Barriers}

Due to the conflicts with some countries in Europe and the United States, the requirements of trade barriers control on the high-tech products are getting higher and higher. Therefore, some measures are necessary to be developed to resist the technical barriers to trade. On the 
one hand, it needs to high-tech industries vigorously. As long as the quality of our high-tech products is good enough, the impact of trade barriers will be less. On the other hand, it can be found that some countries in Europe and the United States attach great importance to environmental protection from the packaging and labeling of products, which is also a major factor that hinders the export of high-tech products. In order to ensure that high-tech products in Fujian Province meet international standards, relevant enterprises in Fujian Province should implement relevant methods to improve product quality, enhance its technical level, and produce the packaging and labels of products in accordance with regulations [9].

\section{CONCLUSIONS}

Although Fujian high-tech products export developed continuously, there are still many problems to be solved, and in many places, it still to be improved. Therefore, the study of Fujian high-tech products export has an important practical significance to increase the export of related products. This paper studied the status quo and problems of the export of high-tech products in Fujian Province, which is believed that we also focus on the investment and the research and development of new products in the future. The state shall support the development of high-tech industries. The science and technology management departments will strengthen the "incubation" and support of the small and medium-sized science and technology enterprises. Firstly, it is necessary to establish high-tech entrepreneurship service system in order to promote the construction of high-tech enterprises actively. The development mode is that small and medium-sized enterprises need to strengthen the service support for these high-tech enterprises, especially in the entrepreneurial period, to promote the rapid development of entrepreneurship and the growth of small and medium-sized enterprises. Secondly, it is necessary to create a business fund for small and medium-sized enterprises, strengthen the transformation of scientific and technological achievements, which will bring rapid development for small and medium-sized enterprises, and even become large scientific and technological innovative enterprises. Finally, whereas the stricter trend of green environmental protection among various countries (especially European and American countries) on technical barriers to trade, it needs to be emphasized that protecting the environment is important, and permeate the concept of green environmental protection into all links of product development. In general, increasing the export of high-tech products in Fujian Province requires the joint efforts of the people, the government and enterprises. Through optimizing hightech product institutions and strengthening the quality and quality of products, it can lead the high-tech industry in Fujian Province to a higher level, so as to improve its own competitiveness.

\section{ACKNOWLEDGMENTS}

Project source: 2020 Fuzhou Theoretical System of Socialism with Chinese Characteristics, "Scientific and Technological Innovation" promoting Fuzhou highquality development beyond the research, Project No.: 2020C02

\section{REFERENCES}

[1] ZENG Hao, XIA Siwen, LI Xiaomei. The Status Quo, Dilemma and Countermeasures of the Export of High-tech Products in Guangdong Province [J]. Practice in Foreign Economic Relations and Trade, 2019(04): 22-25.

[2] MO Jieling Research on the Status Quo of the Export of High-tech Products in Dongguan [J]. Inner Mongolia Coal Economy, 2018(19): 13-14.

[3] YANG Ailong, DONG Hongfei. The Status Quo and Countermeasures of the Export of High-tech Products in China [J]. Times Finance, 2018(18): 210.

[4] GONG Ying. Research on Status Quo and Development Countermeasures of the Export of High-tech Products in Chongqing [J]. Rural Economy and Science-Technology, 2017, 28(01): 171-172.

[5] LIU Erzhen, LV Yuhua. Research on the Status Quo of the Export of High-tech Products [J]. Journal of Lanzhou Institute of Technology, 2016, 23(02): 110-113.

[6] XU Zhiyun. Analysis on Status Quo and Countermeasures of the Export of High-tech Products in Fujian [J]. Journal of Fujian Commercial College, 2014(02): 30-35.

[7] TAN Yishu. An Empirical Analysis of Factors Affecting trade in High-tech Products Intraindustry Trade Between China and the United States [J]. Journal of Hunan Industry Polytechnic, 2019(19). 26-30+39.

[8] WANG Chunyu, HU Haichen, and ZHENG Xuedang. Export Dynamic of China's High-tech Products: Facts, Analysis and Countermeasures [J]. Northern Economy and Trade, 2018(12). 11-14.

[9] JIANG Xiaozhen, LIN Shuang. Study on Countermeasures for the Export of High-tech Products -- Taking Fujian as an Example [J]. The School of Economics \& Management at Fuzhou University of International Studies and Trade, 2019, 20 (04), 33-37. 